\title{
A Função Docente em Medicina e a Formação/Educação Permanente do Professor
}

Nildo Alves Batista' Sylvia Helena Souzo da Silva

\begin{abstract}
RESURO
so considerar a docencia no panorama atual da escola mética brasileira, enfoca-se o exercicio da funçăo duccute $\mathrm{cm}$ Medicina, caacterizando suas especificidades es singularidades. A partir destes parametros, aborda-se o desafio de formar o professor de Medicina numa perspectiva de educaça permantentc. Este desatio figura como nukkar no processo de transformaça da educaçao médica to Brasil.
\end{abstract}

\section{A INSERÇĀO DOCENTE NO CONTEXTO DA ESCOLA MÉDICA BRASILEIRA}

No bojo da história do ensino superior brasileiro insere-se a trajetória da escola médica: instituição historicamente construída no Brasil a partir do século XIX, guarda tradiçōes, ritos, movimentos singulares que se intercruzam com os dilemas e contradiçōes que marcam a vida acadêmica nacional.

A escola médica traduz processos diferenciados do que se tem considerado cumo educação médica: us traços de multidisciplinaridade, abrangéncia e articulação entre us campx)s do conhecimento, das habilidades e das atitudes, os contornos assumidos em relaçăo ao processo ensinoaprendizagem sāo todos elementos que tèm sido conjugados de diversas maneiras.

Esta diversidade configurn uma situnção atual do cussino médico no Pa ís que representa o desafio de pensar a transformação da educação médica articulada ao enfrentamento do estado atual da Medicina e do cenário científico, projetando o futuro com os incertos e nublados dados do presente. No dizer de Schraiber (1989:127). "A proposição de novas práticas que, como tentativa de resposta a contradiçōes reais da prática $c$ da educação médica, nāo tenha o sentido de reapresentar parte do processo de elaboração das representa̧̧ōes ideológicas que apenas aparentam superar as contradicōes estruturais só pode ser buscada no reconhecimento das próprias contradiçōes em que são rcalizadas aquelas práticas".

\footnotetext{
- livre-Docente em Edurasdo Medisa (Unifesp/tirM). Dize ctodo Centro de Inesenvolvimesto do tinsino Superier em Saúdu - Cectens - Unifusp/Fr.M

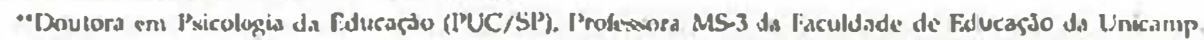


Este reconhecimentoorientou uma pesquisa realizada pela Cinaem $^{3}$ (Comissāo Interinstitucional de Avaliaçāo do Ensino Médico), que, a partir de uma leitura da realidade das escolas médicas brasileiras (EMBs), delineou um processo de investigação dos modelos pedagógicos existentes que explicitou a escola que se tem e a escola que se deseja.

A análise situacional - a escola médica que se tem - mostrou que: "a descrição do processo de formação revela a hegemonia absoluta dos conteúdos programáticos que permitem a compreensão do processo saúde-doença centrado no individuo biologico. Desvenda a semiologia como instrumental de traba.lho que articula a utilizaçāo do conhecimento biológico na abordagem dos distúrbios fisiomorfológicos e assegura a reprodutividade da prática médica, funcionando como instituinte da clinica moderna fundamentada no método positivista” (Cinaem - Modelo Pedagógico, 1997:36).

Já a projeçāo feita - a situação desejada - traduziu a expectativa de que as EMBs privilegiem a inserção precoce dos alunos em a tiv idades práticas, a introduçảo de técricas capazes de instituir uma lógica inovadora nas relações entre conhecimentos básicos e profissionalizantes e a integraçāo das atividades prátičàs, de ensino e pesquisa (Cínaem, 1997).

Entre o real vivido e o ideal projetado, quem é, hoje, o professor no ensino médico brasileiro?

A pesquisa da Cinaem nos traz dados importantes sobre o docente de Medicina, dentre os quais se destacam:

- o corpo docente das escolas médicas brasileiras é constituido em sua maioria por homens na faixa de 30 a 49 anos;

- a graduaçāo de mais da metade dos professores foi realizada na própria escola em que atuam;

- a formaçāo dos docentes, em sua grande maioria, localizase na própria Medicina, tendo continuidade nos programas de residência médica. Em nivel stricto sensu, $31 \%$ da amostra (de um universo de 4.193 professores) possuem mestrado e $20 \%$ têm o título de doutor; apenas $7 \%$ eram especialistas em ed ucaçāo;

- somente um quinto atua em regime de dedicaçāo exclusiva, sendo o regime de trabalho mais frequiente o de 20 a 39 horas semanais;
- somente $30 \%$ auferem mais da metade da renda mensal a partir da atividade docente;

- pouco mais de $20 \%$ dedica 20 horas para a pesquisa e/ ou 20 ou mais à assistência ou ao ensino;

- nos últimos dois anos, $54 \%$ proferiram palestras na cidade onde trabalham; $41 \%$ realizaram publicação em periódico nacional e $25 \%$ referiram publicação em revistas internacionais; $21 \%$ publicaram livro ou capítulo de livro e $14,1 \%$ estāo ou estiveram envolvidos em projetos de pesquisa' financiados.

Na discussāo dos dados, os pesquisadores indicam aspectos relevantes para a contextualização dos dilemas que têm marcado a atuação do professor de Medicina e que se refletem na educação médica e na sua formação. Ressalta-se: "os achados anteriores e o pequeno vínculo da amostra estudada com a produçāo do conhecimento parecem indicar que o trabalho médico como docente não se configura como uma profissão. Em outras palavras, para a grande maioria dos entrevistados, a docência constituiu-se como atividade complementar à profissão médica. (...) Ainda que a docência nāo se configure como uma profissāo plena para os médicos, induzindo uma educação médica reprodutiva, pós-graduação senso estrito e trabalho em dedicação exclusiva foram variáveis chaves na explicação do desempenlıo docente" (Cinaem - Relatório Geral, 1997:17-31).

Estes resultados, quando cruzados com os dados obtidos acerca do desempenho cognitivo e de habilidades práticas dos alunos e sobre os modelos pedagógicos concretizados nas EMBs, possibilitam uma visibilidade fecunda das interdeterminações que articulam os três eixos investigados no Projeto Cinaem (corpo docente, médico formando e modelo pedagógico), bem como o lugar que a fornaçâo docente ocupa nesse contexto.

Considerando os resultados dos alunos e o desempenho docente, concluem os pesquisadores:

"A semelhança estrutural no desempenho dos alunos das escolas avaliadas revela a necessidade de um esforço solidário e criativo para a reposição imediata de novos paradigmas para a educação médica, que impliqquem na transformaçāo das práticas de ensino e avaliação adotadas, o que envolve

3. Sobre u delineasnemo muetodológico do Prajeto. bem como seths ubjetiros 6 filosofia. ver "Aeraliafio das Esculas Mélticas Brasilsirns - 20 Jase", 1994 e "Aonliasto do Ensino Meidico no Brnsil - Re'atório Geral". 1997. 
obrigatoriamente a discussāo da especificidade da docência médica em seus aspectos de formaçāo, regime de trabalho e inserçāo nas atividades do curso de graduaçāo" (Cinaem Relatório Geral, 1997).

Os dados referentes ao modelo pedagógico das escolas médicas e a o professor permitiram as seguintes reflexōes:

"A política de incentivo à capacitaçāo profissional e à carreira docente é deficiente. Assim, os professores apresentam qualificaçāo técnica e pedagógica insatisfatória. Suas atividades sāo avaliadas de forma inadequada. São mal remunerados, dedicam pouco tempo à EM, e se mostram pouco motivados.

A formaçāo dos docentes bem como sua inserçāo na docência de maneira secundária, em relaçāo à atuação profissional da escola, tendem a, por inércia, estimular a manutençāo do modelo hegemônico (...) a concepçāo biologicista de abordagem do processo saúde/doença se mantém estruturalmente e se reproduz através do modelo flexneriano de ensino médico" (Cinaem - Modelo Pedagógico, 1997: 13-36).

\section{O EXERCICIO DA FUNÇĀO DOCENTE EM MEDICINA}

Nāo há como analisar a formação do prnfessor de Medicina sem ter clareza das especificidades que envolvem a docência na área médica:

"Ao professor de medicina é exigido um duplo esforço: de um lado pelos pacientes, que deles esperam apurados conhecimentos técnico-científicos e, de outro lado, requerido como professor, de quem se exige ampla bagagem de conceitos e conhecimentos, além de atitude criativa para tornar conseqüente a relaçāo docente/aluno" (Silva, 1982:7).

^ contribuiçāo do professor de Medicina é considerada fundamental para a reorientaçāo da educaçāo médica, ampliando as perspectivas de transformaçōes dos cursos médicos, principalmente no que se refere ao cotidiano pedagógico de experiências curriculares e metodológicas que privilegiem a construçāodo conhecimento, a interdisciplinaridade e a postura mediadora do professor na interaçāo com o aluno (Sobral, 1987; Passarelli, 1996; Batista, 1997).

Brito \& Siqueira (1993) afirmam, entretanto, que muitos professores de Medicina "nāo possuem qualquer preparo di- dático-pedagógico, e que esse preparo, em muitos casos, se faz meramente instrumental, concebendo-se uma didática autônoma, com preceitos universais que se aplicariam aos diferentes 'conteúdos' e 'finalidades' de áreas especificas" (p.7).

A questāo do preparo do professor de Medicina no que se refere aos aspectos propriamente pedagógicos da açāo docente nāo tem, geralmente, merecido atençāo.

Diferentemente de outras áreas, especialmente das ciências humanas, a graduaçāo c a especializaçāo do médico nāo têm como objetivo a formaçāo de um professor.

Segundo Grigoli (1990:41), “o professor, via de regra, vai intuitiva e empiricamente construindo a sua própria didática calcada nos modelos que conheceu como aluno e no bom senso que o ajuda a 'filtrar' os procedimentos que 'funcionam'. Desse processo resulta, com o passar do tempo, um 'jeito' de organizar c conduzir o ensino que, geralmente, nāo chega a ser tomado como reflexāo nem pelo professor individualmente e, menos ainda, pelo conjunto de professores que lecionam um dado curso".

Na maioria das vezes, o professor de Medicina é contratado tendo-se como critério apenas a qualidade de seu desempenho como profissional e/ou pesquisador. Fica implícito que a compctència profissional e/ou acadêmica assegura a compctência didática. An contrário de algumas outras áreas, nāo se exige formaçāo sistematizada que instrumentalize a sua maneira de conceber e desenvolver o processo ensinoaprendizagem.

Especialmente na Universidade Pública, tem sido conferido um status de menor importância à funçāo do ensino, particularmente da graduaçāo, quando comparada à pesquisa. Os critérios de progressāo na carrcira docente fundamentam-se muito mais na produçāo científica que no exercicio da docència.

O professor nāo se sente particularmente motivado para envolver-se com projetos pedagógicos que visem à melhoria do processo ensino-aprendizagem c pode, até mesmo, apresentar resistência, por desacreditar ou por perceber que "desvios" de suas atividades de pesquisa para aumentar suas atividades de ensino possam representar prejuizo para a sua carreira acadêmica.

É preciso que o professor tenha clareza da relaçāo entre o método, as finalidades da educaçāo, os objetivos de sua disci- 
plina, os conteúdos de ensino e as possibilidades de aprendizado de seus alunos.

É evidente a relevància da dimensāo pedagógica do trabalho do professor de Medicina: repensá-la significa repensar a direçāo dos compromissos da própria Escola Médica. E, no interior desta escola médica, como podemos configurar a funçāo docente em Medicina?

Uma resposta possivel assume a referida função como caracterizada pela complexidade, diversidade, multideterminaçăo, dinamicidade, exigindo a interdisciplinaridade.

A formação em Medicina implica a triangulaçāo entre conhecimentos, habilidades e atitudes, concretizada nos espaços de ensino, pesquisa e extensão que envolvem os condicionantes relativos à missão institucional c ao processo de desenvolvimento curricular, ao planejamento de ensino, à interaçāo professor-aluno, à produção de conhecimento sobre a própria funçāo e à atividade assistencial.

Freqüentemente, os docentes desconhecem a estrutura curricular formal do curso e a relação das disciplinas entre si. $\mathbf{O}$ conhecimento e a compreensāo da proposta curricular são fundamentais para uma atuação profissional de forma consciente, reflexiva e integrada.

Segundo Hossne (1994:77), "o professor, durante o percurso como estudante, concordou e discordou, elogiou ou criticou, se entusiasmou ou execrou atitudes de seus professores de entāo. Ao se tornar professor, nem sempre pōe em prática as correçōes de rumo que desejava que seus professcores tivessem feito e também nem sempre consegue adotar e seguir rumos que considerava, entāo, os melhores. Não raras vezes, o professor adota com mais vigor as atitudes que the pareciam (e talvez no fundo the pareçam) negativas".

O documento preparatório da Conferéncia Mundial sobre Educaçāo Médica de 1988 afirma que um corpo docente qualificado e dedicadoé essencial para o sucesso do curso de Medicina.

Sobral (1987) comenta que a educaçāo permanente do corpo docente possibilita a reorientação da educação médica em face dos desafios de ordem tecnológica e social. Nessa educação permanente, salienta a concepção pedagógica evolutiva, em termos de instrumentos e estratégias, meios e métodos educativos, centrados no estudante, base ados em problemas pertinentes ao contexto global, flexíveis e individualizados, para atender à necessidade de formaçāo de médicos com maturidade profissional c social.

Analisando os avanços tecnológicos, Passarelli (1996) comenta que os novos paradigmas da educação consideram que os alunos devem ser preparados para conviver numa sociedade em constante mudança, serem construtores do seu conhecimento e sujeitos do processo, em que a "intuição" e a "descoberta" são elementos privilegiados.

Nesse modelo, os professores, de transmissores da informaçāo, passam a facilitadores do processo de aprendizagem, no qual aprender a aprender é privilégio em detrimento da memorizaçāo de fatos.

$\mathrm{Na}$ escola médica, freqüentemente, as açōes ligadas à dimensão pedagógica da funçāo docente nāo têm sido objeto de maiores preocupaçōes. Parte-se, em geral, do princípio de que o professor que teve uma sólida formação na especialidade em que deve atuar como docente encontra! "naturalmente" os meios para ensiná-la, no que se refere tanto ao corpo de conhecimentos de sua área, quanto ao desenvolvimento de formas de pensamento e habilidades técnicas essenciais à atuaçāo profissional do egresso de sua disciplina.

Constata-se, inclusive, uma tendência para encarar com ceticismo ou descaso os aspectos pedagógicos da docência de nivel superior. Espera-se do professor de Medicina que seja, antes de tudo e sobretudo, um profundo conhecedor do assunto que deve ensinar, como se apenas esse aspecto assegurasse sua competência didática.

As açōes de ensino tendem a permanecer em segundo plano, não sendo pensadas pelos professores.

\section{O DESAFIO DA FORMAÇĀO DO PROFESSOR DE MEDICINA: UM PROCESSO DE EDUCAÇĀO PERMANENTE}

Considerando-se a realidade acima descrita, o desafio de formar o professor de Medicina figura como nuclear no processo de transformaçāo da escola médica brasileira.

Mas qual a concepção de formação que assumimos ao projetarmos uma experiência de formação permanente do docente do curso médico?

Trata-se de uma questāo importante, uma vez que formar professores adquire, a cada momento histórico, níveis e for- 
matos diferentes, e remete a opçōes feitas no interior das relaçōes sociais de produçāo.

Nas últimas décadas, a formação die professores tem incorporado uma concepçāo linear e simplista dos processos de ensino, reduzidos a dois componentes: um componente científico-cultural, que pretende assegurar o conhecimento do conteúdo a ensinar; e outro psicopedagógico, que permite aprender como atuar eficazmente na sala de aula (Gomez, 1992).

O componente psicopedagógico engloba o conhecimento de princípios, leis e teorias que explicam o processo ensinoaprendizagem e sua aplicação prática, de tal forma que o docente adquira as competências e capacidades para uma intervençāo eficaz.

Tal racionalidade técnica na visāo do processo de formaçāo do professor apresenta limites, às vezes, significativos. A tecnologia educacional, especialmente em Medicina, nāo pode deixar de considerar o aspecto da prática diária, na qual a complexidade, a singularidade, o conflito de valores e a intersubjetividade estāo presentes.

A realidade social implicita no processo nāo pode ser restrita a problemas meramente instrumentais, em que a tarefa docente se resuma a uma correta escolha e aplicação de meios e procedimentos, embora existam situaçỏes em que a forma mais adequada de intervenção consista na adoção destes princípios.

Diferentemente da racionalidade técnica, a racionalidade prática analisa como o docente utiliza o conhecimento cientifico, elabora rotinas, experimenta hipóteses de trabalho, utiliza técnicas e instrumentos conhecidos, e recria estratégias.

Segundo Schon (1992), o processo ocorre pelo conhecimento na açāo, reflexão na ação e sobre a açāo. O conhecimento na açāo manifesta-se no saber fazer. A reflexāo na açāo pressupōe um processo de diálogo e interaçāo com a situaçāoproblema e exige intervençāo efetiva. A reflexāo sobre a açāo é a análise posterior das caracteristicas e processos da açāo.

Eo processo de reflexāoaçāo o mecanismo que possibilita uma abordangem metodológica racional e dinâmica ao professor, não se pautando em modelos acabados ou regras previamente estabelecidas (Luckesi, 1996).

As reflexōes e análises até aqui realizadas nos remetem a uma concepçāo sobre a formaçāo em Medicina: entende-se formar como "proporcionar uma forma, mas nāo modelar uma forma. Ao formar, estamos oferecendo um continente e uma matriz a partir dos quais algo possa vir-a-ser"; e treinar como "trazer para si, puxar. Quem puxa coloca-se à frente, atraindo o treinando, mas mantendo-se sempre a uma certa distância. Deixa sempre a desejar porque já reconhece no treinando a existência de recursos próprios a serem mobilizados no treinamento. No exercício deste desejo e na mobilizaçāo e aperfeiçoamento destes recursos, o treinamento transcorre" (Figueiredo, 1996: 117-119).

Comprometer-se com essas duas dimensỏes significa assumir que ser professor constitui um processo de educação permanente, caracterizado como um espaço de apropriaçāo de conhecimentos relativos a saber ensinar, estimulan. do a busca de outros saberes e fecundando uma inquietaçāo continua com o já conhecido, motivando viver a docência universitária em toda a sua imponderabilidade, surpresa, criaçāo e dialética na relaçāo com o novo(Batista, 1997; Sousa da Silva, 1997).

Isto conduz ao entendimento de uma prática docente transformadora que identifique nāo apenas "o que" ou "quanto" da aprendizagem, mas, sobretudo, se o modo "como" ela se processou tornou o aluno mais competente, dando-lhe conhecimentos sólidos, atualizados e cientificamente comprovados, e dominio das habilidades e atitudes necessárias ao exercício da profissāo médica.

Reafirma-se, portanto, que o processo formativo é complexo e múltiplo; longe, portanto, de traduzir-se apenas num modelo de prática de formaçāo. Formar professores nāo é o ponto único do projeto de transformar a educaçāo, nem pode ser buscado apenas nos lïmites das instituiçōes formadoras.

A velocidade da transformação do conhecimento, as novas demandas para a formaçāo de profissionais, o entendimento de que formar nāo se esgota num curso e/ou ao final de um periodo de estudos, os limites de qualquer proposta de formaçāo inicial e a necessidade de tomar a prática como objeto de análise, investigaçāo e intervençāo definem um panorama propício para práticas de formação permanente.

Entende-se a formação permanente como um processo concretizado por sujeitos históricos, permeado pela intencionalidade e por íntima relaçāo com a prática que o docente materializa em seu trabalho pedagógico, constituindo um instrumento de transformação por meio da reelaboração dos saberes docentes. 
Distanciamo-nos, assim, da perspectiva de treinamento como mero adestramento para tarefas a serem reproduzidas ou de reciclagem como simples atualizaçāo pedagógica, episódica, acrítica e descontextualizada (Marin, 1995).

Articulada a esse entendimento de formação permanente do professor de Medicina, situa-se a compreensāo de que as transformações do mundo do trabalho exigem novos mecanismos de apropriaçāo do conhecimento, valorizando a reflexảo, a prática, os saberes da experiència, bem como ampliando as oportunidades de troca e interlocuçāo.

\section{SUMMARY}

Considering leaching, within the Brazilian Medical Srhonl present context, the role of the professor of medicine is focused on its specificity and singularities from these paratneters. the challenge of the medical professor formation is approached under a permanent education perspective. This clallenge is essential in the transformation process of the medical education in Brazil.

\section{KEY WOKDS}

- Medical education:

- Professor of Medicine:

Professor formation.

\section{REFERENCIAS BIBLIOGRÁFICAS}

1. BATISTA, N. A. Conhecimento, Experiência e Formaşān: do médico ao professor de medicina. Estudo sobre a Disciplina Formaçảo Didático-Pedagógica em Saúde nos Cursos de Pós-Graduaçāo da Unifcsp/EPM. Sāo Paulo, Tese de Livre Docència, Unifesp/EPM, 1997.

2. BRITTO, D. T. S. \& SIQUEIRA, V. H. F. Resgatando a Saúde como Eixo de formaçāo de Profissional de Saúde: Uma Proposta para a Formaçâo Didático-Pedagógica dos Docentes. 1993. (mimeografado)

3. CINAEM. Avaliaçāo das Escolas Médicas Brasileiras. Projeto de Implanlaçāo e Resultados da 1ª fase, 1994.

4. CINAEM. Avaliaçāo das Escolas Médicas Brasilciras. Rẹlatório do Modelo Pedagógico, 1997. (mimeografado)

5. CINAEM. Avaliação das Escolas Médicas Brasileiras. Relatório Geral, 1997. (mimeografado)

6. FIGUEIREDO, L. C. M. A Preparaçāo do Psicólogo: formação e treinamento. In:
FIGUEIREDO. L.C.M. Revisitando as Psicologias. Sāo Paulo: Vozes, 1996.

7. GOMEZ, A. P. O Pensamento Prático do Professor - a formaçăo doprofessor como profissional reflexivo. In: NOVOA, A. (org.). Os Professores e a sua Formaçāo. Lisboa: Dom Quixote, 1992.

8. GRIGOLI, J. A Sala de aula na Universidade na Visāo de seus Alunos - Um Estudo sobre a prática pedagógica na Universidade. Sāo Paulo, Tese de Doutoramento, PUC-SP, 1990.

9. HOSNNE, W. S. Relaçāo Professor-Aluno: Inquietaçōes Indagaçōes - Ética. Rev. bras. educ. méd. Rio de Janeiro, v. 18, n. 2, p. 75-82, 1994.

10. LUCKESI, C. et al. Fazer Universidade: Uma proposta metodológica. Sāo Paulo: Cortez, 4๋ ed., 1996.

11. MARIN, A. J. Educação Continuada: Introduçāo a uma Análise de Termos e Concepçōes. In: Cadernos Cedes. Campinas: Papirus, n. 36, p. 13-20, 1995.

12. PASSARELLI, B. Multimídia na Educaçăo. A Experiência da "Escola do Futuro". In: SOARES, I.O. \& Gotlieb, L. Comunicaçāo e Plano Decenal de Educação: rumo ao ano 2003. Brasília: MEC, 1996.

13. SCHÖN, D. La Formación de Profissionales reflexivos hacia un nuevo diseno de la enseñanza y el aprendizage en las profesores. Barcelona: Paidós, 1992.

14. SCHRAIBER, L. Educação médica e Capitalismo. Sāo Paulo/Rio de Janeiro: Hucitec e Abrašo, 1989.

15. SILVA, P. C. T. Assessoria Pedagógica. Rev. Bras. Educ. Méd. Rio de Janeiro, v.6, n.1, p.7-8, 1982.

16. SOUSA DA SILVA, S. H. Professor de Medicina: Diálogos sobre sua formaçāo docente. Sảo Paulo, Tese de Doutoramento, PUC-SP, 1997.

17. SOBRAL, F. A. F. O Ensino Superior e a Pesquisa Científica e Tecnológica. In: Martins, C. B. Ensino Superior Brasileiro: transformaçōes e perspectivas. Sāo Paulo: Brasiliense, 1987.

Endereço para correspondència:

Rua Coronel Lisboa, 837 - Vila Clementino

040020-041 - Sāo Paulo - SP 